University of Nebraska - Lincoln

DigitalCommons@University of Nebraska - Lincoln

1992

\title{
Perceptions of an Innovative Climate: Examining the Role of Divisional Affiliation, Work Group Interaction, and Leader/ Subordinate Exchange
}

\author{
Kenneth Dunegan \\ Cleveland State University \\ Pamela S. Tierney \\ Portland State University \\ Dennis Duchon \\ University of Nebraska-Lincoln, dduchon2@unl.edu
}

Follow this and additional works at: https://digitalcommons.unl.edu/managementfacpub

Part of the Management Sciences and Quantitative Methods Commons

Dunegan, Kenneth; Tierney, Pamela S.; and Duchon, Dennis, "Perceptions of an Innovative Climate: Examining the Role of Divisional Affiliation, Work Group Interaction, and Leader/Subordinate Exchange" (1992). Management Department Faculty Publications. 88.

https://digitalcommons.unl.edu/managementfacpub/88

This Article is brought to you for free and open access by the Management Department at DigitalCommons@University of Nebraska - Lincoln. It has been accepted for inclusion in Management Department Faculty Publications by an authorized administrator of DigitalCommons@University of Nebraska - Lincoln. 


\title{
Perceptions of an Innovative Climate: Examining the Role of Divisional Affiliation, Work Group Interaction, and Leader/ Subordinate Exchange
}

\author{
Kenneth J. Dunegan, Pamela Tierney, and Dennis Duchon
}

\begin{abstract}
Results from a cross-sectional field study with 198 members of an international chemical company suggest that divisional affiliation, work group interactions (WGX), and the quality of exchange between leader and subordinate (LMX) significantly predict employee perceptions of climate factors believed to foster innovative activities. Tests also indicate that LMX remains a significant predictor of five of the six climate variables measured, even after controlling for divisional affiliation and the quality of work group exchanges (WGX). Further analyses reveal that the interaction between WGX and LMX accounts for significant and unique variance on all six of the climate factors studied in this investigation. Results are discussed in terms of their implications for managerial practice and future research.
\end{abstract}

\section{INTRODUCTION}

$\mathrm{N}$ AYAK and Ketteringham [27] argue that innovation usually occurs because individuals become intensely curious about something and are willing to pursue an idea despite opposition. This perspective clearly positions people as the crucial ingredient in a successful innovation endeavor. Yet many researchers are coming to the conclusion that having the right people is not always sufficient for achieving innovative solutions to organizational problems [2]. Instead, many believe that innovative thinking is something which must be actively cultivated by the organization [50], and that establishing a work climate compatible with innovation is as much a part of the equation as the people themselves (e.g., [1], [17], [24], [29]-[31].

For example, in a study conducted by Abbey and Dickson [1] in the semiconductor industry, it was found that

Manuscript received June 1990; revised February 1991. This work was supported by the Center for Innovation Management Studies. Additional support was provided through the Research Challenge Grant Program at Cleveland State University.

K. J. Dunegan is with the Department of Management and Labor, Cleveland State University, Cleveland, $\mathrm{OH} 44115$.

P. Tierney is with the School of Business Administration, Portland State University, Portland, OR 97207-0751.

D. Duchon is with the Department of Management, University of Texas at San Antonio, TX 78285.

IEEE Log Number 9201298. the climate perceived by R \& D workers significantly influenced all stages of the innovation process (e.g., idea generation, initiation, adoption, and implementation). Similar linkages between work climate and innovative behaviors are reported by Baker and Freeland [6], Sapolsky [35], Vegso [51], and others [49], [47]. Studies have even documented that creative thinking, an important component of the innovation process, is significantly enhanced by establishing a conducive work climate [4], [44]- [46]. Thus, not only is there an intuitive link between work climate and innovative activities, but findings such as those cited above are establishing a growing body of research which demonstrates an empirically supported linkage as well.

In fact, the importance of work climate in fostering innovativeness is becoming widely accepted. Amabile [2] suggests that “... at a gross level, personal factors such as general intelligence, experience in the field, and ability to think creatively are the major influences on output of creative ideas. But, assuming that hiring practices at major corporations select individuals who exhibit relatively high levels of these personal qualities, the variance above this baseline may well be accounted for primarily by factors in the work environment." (p. 128) Similarly, Paolillo and Brown [30] state that work climate is at least as important in the innovative process as characteristics of the people involved. Paolillo and Brown go on to say that managers should not assume they can simply hire good people and let the system run by itself. Rather, it is essential to create and sustain a work climate which is supportive of innovative behaviors.

Several theorists suggest that managers may play a key role in this endeavor. Kanter [21] and James and James [18], for example, maintain that managers are a primary source for the signals from which subordinates construct perceptions of their work group's climate. Since employee perceptions of climate conditions have been strongly linked with innovation initiation, adoption, and implementation [1], understanding how leader/subordinate relationships influence those perceptions is an important area 
of inquiry for innovation researchers. ${ }^{1}$ A recent study by Kozlowski and Doherty [23] demonstrated that the quality of exchange between the leader and subordinate was significantly correlated with perceptions of a number of climate factors believed to foster innovative activities, but this line of inquiry is still in its nascent stages.

Clearly, however, managers are not the only source from which perceptions of the work climate can emerge. The nature of the tasks performed in various functional areas of an organization, and the underlying qualifications of employees needed to perform those tasks, may introduce preexisting structural conditions [30], which are more or less conducive to an innovative climate. In other words, we might expect inherent differences in the climates experienced by employees in manufacturing and $\mathrm{R} \& \mathrm{D}$ divisions, for example, simply because of the structural characteristics endemic to these functional areas [28]. This isn't to say that an innovative climate is more important in one division compared to another, but rather that baseline conditions which foster or constrain innovation may not be equivalent across functional areas. Thus, with naturally occurring differences in baseline conditions, we might also expect naturally occurring differences in employee perceptions.

A third source of employee perceptions of climate will come from exchanges among members of the work group itself [1], [18]. Since climate has a strong subjectively-based component [37], [38], much of what a subordinate comes to perceive will be the result of socially constructed interactions. That is, the attitudes and perceptions an employee develops can, in large part, be a function of the attitudes and perceptions of the group within which he/she works [34]. Therefore, regardless of whether or not a manager is attempting to foster an innovative climate, the norms [33] and cohesiveness [42] of work group members may either counteract or augment a manager's efforts [22]. Said differently, perceptions of how conducive

\footnotetext{
${ }^{1}$ It is worth noting that there is some debate regarding the nature of climate as a research construct. The issue is whether climate exists as an organizational reality [10], or as a manifestation of an individual's subjective perceptions [37], [39]. In other words, the question revolves around whether climate is an objective or subjective property. The debate has been somewhat defused by suggestions that there are probably several types of climates within the realm of a single organization [40]. James and Jones [19], for example, suggest that individual leve perceptions of climate factors tap into a "psychological climate," a climate which will be more subjective and idiosyncratic. This does not rule out the possibility, however, that there may be consensus of perceptions among organizational members, indicating the presence of a more objective "organizational climate" [19]. From a methodological point of view, the possibility of several climates existing within the same organization raises design problems. Specifically, which climate should be measured? Powell and Butterfield [32] and Schneider and Reichers [40] suggest that the climate measure chosen should be consistent with the intent of the research investigation. Since Nayak and Ketteringham [27] argue that the genesis of most innovations are individuals responding to their own curiosity, and since this is a study of climate factors germane to the innovative process, then it seemed fitting, at least for purposes of this investigation, that climate should be operationalized at the individual level. Thus, consistent with most innovation research cited in this paper, we chose to assess climate by measuring individual employee perceptions of a number of factors shown to be correlated with innovative behaviors.
}

the climate is to innovative actions may be due to the quality of interaction an employee has with other work group members.

The purpose of this study is not so much to empirically validate whether or not the three factors of functional affiliation, work group interactions, and leader/subordinate exchange are related to employee perceptions. Indeed, previous studies offer evidence which already indicates these relationships exist. Rather, this investigation is intended to assess the manner in which these three sources interact to explain differences in the experienced work climate. But perhaps more importantly from a managerial perspective, the study also will examine the incremental contribution made by the leader/subordinate relationship, over and above any variance explained by the other two factors. The significance focusing on this particular variable lies in the relative control a manager has over the three factors.

Since the types of tasks performed in different divisions may require dissimilar skills, talents, and training, it is likely that differences will exist between the individuals who are hired to perform those tasks. While a manager may be empowered to make hiring, firing, and transferring decisions, once a person is in a certain division, the idiosyncratic characteristics of task and employee are a relatively stable "given." That is, short of redesigning tasks and the concomitant skills necessary for task performance, a manager is not likely to be able to do much to change the inherent climate variations which may exist across divisional boundaries.

Similarly, the dynamics which emerge among work group members and the degree to which members are able to develop positive interactions with each other will, in large part, be a function of individual personalities, needs, and motivations of the various members. While a manager is not powerless to affect work group dynamics, most of what he/she can do is limited to indirect strategies (i.e., redesigning tasks, changing group member membership through hiring, firing, transferring, etc.) Bottom line, a manager can only provide the opportunity for positive exchanges among work group members to develop. What emerges cannot be legislated by managerial decree.

On the other hand, of the three sources of climate perceptions discussed above, the quality of exchange which develops between a leader and subordinate will be the one most sensitive to managerial intercessions. In other words, a manager would be in a better position to affect this source of climate perception to a greater degree than either of the other two. Therefore, part of what will be examined in this study is the extent to which the quality of the dyadic exchange (the exchange between manager and subordinate) is able to predict additional variance in perceived climate conditions beyond that predicted by the factors farther removed from managerial control. Said differently, the study will explore whether the dyadic exchange makes a difference in subordinate perceptions, given functional affiliation and the quality of work group interactions. 


\section{METHOD}

\section{A. Sample and Procedure}

This study was part of a research program sponsored by the Center for Innovation Management Studies. Data were collected from 198 employees from three divisions of a large, international chemical company. Participation in the study was completely voluntary and respondents were assured of the confidentiality of all answers. Of those subjects for whom demographic information was available, 169 were men with an average age of 42.5 years and 13 years with the company; 16 were women with an average age of 36.4 and 7.2 years with the company. The three divisions included in the sample were manufacturing ( $n=49), \mathrm{R} \& \mathrm{D}(n=45)$, and corporate-representing the marketing, sales, and administrative arm of the organization $(n=104)$.

Data were collected via questionnaires. Instructions to participants stated that "...this is not a test. There are no right or wrong answers. We simply want to know what your views are. ...W Work quickly. Your initial impression is probably the right one." Participants were given a preaddressed, prepaid envelope in which to mail their completed questionnaires directly to the research team.

\section{B. Measures}

All variables in the study, with the exception of divisional affiliation, were collected with items using a 5-point, Likert-type response scale.

Climate-As indicated earlier, previous studies have already identified a number of climate variables believed to either promote or inhibit innovative activities (cf. [1]-[3], [5], [7], [31], [43], [48]). For purposes of this investigation, six variables were used to evaluate subordinate perceptions of their work climate, the first five of which were adapted from an instrument developed by Welsh and Matthews [53]. Of the six variables, four have been found to be positively correlated with innovative activities (freedom, encouragement, recognition, and coordination); two have been shown to be negatively correlated (disinterest and constraints)

- Freedom: the degree to which subordinates perceived they had been given operational autonomy in performing their tasks. This variable combined responses from five items, scored so that the higher the score the more freedom a subordinate perceived. Internal reliability (Cronbach's alpha) for this variable was 89 .

- Disinterest: the degree to which subordinates believed innovative and creative solutions were not really something the organization cared about. This climate measure was assessed with three items, scored so that the higher the score the greater the perceived level of disinterest. Internal reliability (Cronbach's alpha) for this variable was .81 .

- Recognition: a four-item measure assessing the degree to which subordinates perceived they would be appropriately recognized and rewarded for innovative behaviors. The higher the resulting score, the more respondents felt recognition would be given for innovative actions. Internal reliability (Cronbach's alpha) for this variable was .75 .

- Encouragement: the degree to which subordinates felt encouraged to be innovative because of managerial enthusiasm and overall support for new and creative ideas. Again, scores from five items were combined to create this variable. The higher the score, the more encouraged subordinates felt about being innovative. Internal reliability (Cronbach's alpha) for this variable was .88 .

- Constraints: the degree to which subordinates believed there wasn't sufficient time or resources to allow them to search for creative and innovative solutions. This was a six-item measure. The higher the score the more subordinates perceived constraints were present which inhibited innovative actions. Internal reliability (Cronbach's alpha) for this variable was .65 .

- Coordination: this was a five-item variable adapted from Georgopolous and Mann [11], which assessed the degree to which subordinates believed positive and constructive interactions existed with other, relevant groups in different departments or work units of the organization. Higher scores represented a more positive perception of levels of coordination. Internal reliability (Cronbach's alpha) for this variable was .76 .

Work Group Exchange (WGX)-Seven items from the questionnaire were combined to measure a subordinate's perception of the quality of exchange within his/her work group. Items evaluated such things as commitment, satisfaction, coordination, quality and quantity of tasks performed by members of the respondent's work group. Higher scores represented a more positive exchange between work group members. Internal reliability (Cronbach's alpha) for this variable was .89 .

Leader-Member Exchange (LMX)-Six items from Graen's Leader-Member Exchange scale [8], [9], [13] provided information for evaluating the quality of dyadic interaction between managers and subordinates. This was the same instrument used in the study performed by Kozlowski and Doherty [23], cited earlier. Once again, scoring was done such that higher scores indicated a more positive perception of the dyadic exchange. Internal reliability (Cronbach's alpha) for this variable was .89 .

Divisional Affiliation--Information on divisional affiliation was obtained from archival records provided by the sponsoring organization. For statistical purposes, dummy codes were used to identify whether a respondent was a member of the manufacturing, $\mathrm{R} \& \mathrm{D}$, or corporate divisions.

\section{ANALYSES AND RESULTS}

Descriptive statistics (means and standard deviations) and correlations among the climate and exchange vari- 
TABLE I

CORRElations AND DESCRIPTIVE STATISTICS

\begin{tabular}{|c|c|c|c|c|c|c|c|c|c|}
\hline & \multirow[b]{2}{*}{ Mean Std. } & \multicolumn{8}{|c|}{ Intercorrelations } \\
\hline & & 1. & 2. & 3. & 4. & 5. & 6. & 7. & 8. \\
\hline 1. Freedom & 15.094 .74 & .89 & & & & & & & \\
\hline 2. Disinterest & 7.312 .73 & $-.42^{* * *}$ & .81 & & & & & & \\
\hline 3. Recognition & 10.233 .14 & $.41^{* * *}$ & $-.46^{* * *}$ & .75 & & & & & \\
\hline 4. Encouragement & 17.574 .42 & $.46^{* * *}$ & $-.36^{* * *}$ & $47^{* * *}$ & .88 & & & & \\
\hline 5. Constraints & 17.203 .80 & $-39 * * *$ & $44^{* * *}$ & $-.34 * * *$ & $38 * * *$ & .65 & & & \\
\hline 6. Coordination & 14.003 .39 & $.13^{\#}$ & $-.31 * * *$ & $.18^{* *}$ & .07 & $-.27^{* * *}$ & .76 & & \\
\hline 7. WGX & 20.735 .15 & $.24^{* * *}$ & $-.24^{* * *}$ & $18^{* *}$ & $.25^{* * *}$ & $-.23^{* *}$ & $.27^{* * *}$ & .89 & \\
\hline 8. LMX & 21.914 .87 & $.34 * * *$ & $-.24^{* * *}$ & $.41^{* * *}$ & $.69^{* * *}$ & $-.21^{* *}$ & .07 & $.34^{* * *}$ & .89 \\
\hline
\end{tabular}

ables are presented in Table I. Several items are worth noting from this table. First, there were significant correlations between work group exchanges (WGX) and the six climate variables, all in the expected direction (i.e., positive correlations with perceptions of freedom, recognition, encouragement, and coordination; negative correlations with constraints and disinterest). Second, a similar pattern of relationships was found between LMX (the variable assessing the quality of exchange between manager and subordinate) and the climate variables, with the exception of coordination. LMX and coordination were not significantly correlated. Third, the positive and significant relationship between WGX and LMX indicated that subordinates who perceived favorable exchanges with their supervisor were also more likely to report favorable exchanges within the work group.

A final observation from data in Table $I$ is that the climate variables were not independent. That is, strong intercorrelations were present among several of the different measures. Although these results are not surprising, given the measures were all tapping into perceptual issues using a common method (i.e., questionnaire) of collecting information [18], [23], they did suggest that a multivariate analysis precede the examination of how division affiliation, WGX and LMX might interact in predicting variance of individual climate variables. Therefore, the next step was to perform a multivariate analysis of variance (MANOVA), where all six climate factors were simultaneously entered as dependent variables, with division, WGX, LMX, and their interactions as the independent measures. Results from this analysis are shown in Table II.

Basically, findings from the MANOVA supported continuation of the analyses on a univariate level. Even though climate variables were found to be intercorrelated (see Table I), MANOVA results indicated significantly strong $F$ values were present for each of the main effects (i.e., division, WGX, and LMX), as well as two of the interaction terms (i.e., division * LMX, and WGX * LMX). Therefore, to examine relationships on a univariate level, six separate regression models were tested, one for each of the climate variables.

However, as indicated earlier, since part of this investigation was to see whether the exchange between leader
TABLE II

Multivariate Analysis of Variance (MANOVA) Results Testing Relationships Among Divisions, Work Group EXCHANGES (WGX) and LMX WITH all Climate Variables CONSIDERED SiMULTANEOUSLY

\begin{tabular}{lrcl}
\hline $\begin{array}{c}\text { Independent } \\
\text { Variable: }\end{array}$ & d.f. & $\begin{array}{c}\text { Wilks' } \\
\text { Lambda }\end{array}$ & \multicolumn{1}{c}{$F$} \\
\hline Division (D) & 12 & 0.896 & $1.62^{*}$ \\
WGX (W) & 6 & 0.889 & $3.59^{* *}$ \\
LMX (L) & 6 & 0.873 & $4.19^{* * *}$ \\
D $*$ W & 12 & 0.904 & 1.50 \\
D $*$ L & 12 & 0.896 & $1.63^{\#}$ \\
W $* \mathrm{~L}$ & 6 & 0.842 & $5.42^{* * *}$ \\
D $* \mathrm{~W} * \mathrm{~L}$ & 12 & 0.908 & 1.43 \\
\hline
\end{tabular}

${ }^{* * *} p<.001 ;{ }^{* *} p<.01 ;{ }^{*} p<.05 ;{ }^{\#} p<.10$

and subordinate (LMX) could account for significant variance above and beyond divisional affiliation and WGX (the two variables over which a manager has less control), it was important to manipulate the order of entry of the predictor variables. This was accomplished by constructing hierarchical regression models so that LMX was the last predictor variable entered. More specifically, division was entered first, followed by WGX, followed by LMX, then the interaction terms. In this way, LMX would only be tested for significance on the variance remaining after division and WGX had already accounted for any common variance shared between these variables and LMX. Results from these tests are reported in Table III.

As data in Table III indicate, all six models were significant, with the full models accounting for between 14 and $53 \%$ of the variance in the climate factors. There were significant differences in freedom, disinterest, recognition, and encouragement associated with divisional affiliations. Only constraints and coordination were not found to differ between manufacturing, R \& D, and corporate divisions. For informational purposes, mean scores for each climate variable were computed by division and reported in Table IV.

Results shown in Table III also indicate that perceptions of work group exchange (WGX) was a strong and consistent predictor of all six climate variables. That is, beyond any naturally occurring differences brought about by divisional affiliations, the quality of exchange among work group members accounted for significant and unique variance on all climate factors. 
TABLE III

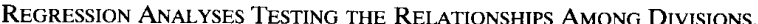
Work Group Exchanges (WGX) and LMX ON Climate Variables

\begin{tabular}{|c|c|c|c|c|c|c|c|}
\hline \multirow{2}{*}{$\begin{array}{l}\text { Climate } \\
\text { Measure }\end{array}$} & \multirow[b]{2}{*}{ d.f. } & \multicolumn{2}{|c|}{ Freedom } & \multicolumn{2}{|c|}{ Disinterest } & \multicolumn{2}{|c|}{ Recognition } \\
\hline & & $F$ & $\overline{R^{2}}$ & $F$ & $\overline{R^{2}}$ & $F$ & $\overline{R^{2}}$ \\
\hline Full Model & 11 & $5.46^{* * *}$ & .25 & $5.59^{* * *}$ & .25 & $6.20^{* * *}$ & .27 \\
\hline Division (D) & 2 & $8.45^{* * *}$ & & $4.40^{* *}$ & & $6.81^{* * * *}$ & \\
\hline WGX (W) & 1 & $11.44^{* * *}$ & & $15.28^{* * *}$ & & $7.85^{* *}$ & \\
\hline LMX (L) & 1 & $14.41^{* * *}$ & & $8.44^{* *}$ & & $31.98^{* * *}$ & \\
\hline $\mathrm{D} * \mathrm{~W}$ & 2 & 0.63 & & 0.49 & & $2.92^{\#}$ & \\
\hline $\mathrm{D} * \mathrm{~L}$ & 2 & $2.80^{\#}$ & & $2.71^{\#}$ & & 0.67 & \\
\hline $\mathrm{W} * \mathrm{~L}$ & 1 & $6.65^{* *}$ & & $12.87^{* * *}$ & & $7.17^{* *}$ & \\
\hline $\mathrm{D} * \mathrm{~W} * \mathbf{L}$ & 2 & 1.79 & & $4.87^{* *}$ & & 0.17 & \\
\hline \multirow{2}{*}{$\begin{array}{l}\text { Climate } \\
\text { Measure }\end{array}$} & & \multicolumn{2}{|c|}{ Encouragement } & \multicolumn{2}{|c|}{ Constraints } & \multicolumn{2}{|c|}{ Coordination } \\
\hline & d.f. & $F$ & $\overline{R^{2}}$ & $F$ & $\overline{R^{2}}$ & $F$ & $R^{2}$ \\
\hline Full Mode & 11 & $19.01^{* * *}$ & .53 & $2.70^{* *}$ & .14 & $3.70^{* * *}$ & .19 \\
\hline Divisio & 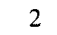 & $4.92^{* *}$ & & 1.26 & & 1.70 & \\
\hline WGX (W) & 1 & $25.49^{* * *}$ & & $12.43^{* * *}$ & & $18.26^{* * *}$ & \\
\hline $\mathrm{LMX}(\mathrm{L}$ & 1 & $162.79^{* * *}$ & & $5.09^{*}$ & & 0.01 & \\
\hline $\mathrm{D} * \mathrm{~W}$ & 2 & 0.89 & & 1.08 & & 0.31 & \\
\hline $\mathrm{D} * \mathrm{~L}$ & 2 & 1.26 & & 0.40 & & 0.46 & \\
\hline $\mathrm{W} * \mathrm{~L}$ & 1 & $5.59^{*}$ & & $6.70^{* *}$ & & $17.32^{* * *}$ & \\
\hline $\mathrm{D} * \mathrm{~W} * \mathbf{L}$ & 2 & 0.55 & & 0.02 & & 0.10 & \\
\hline
\end{tabular}

${ }^{* * *} p<.001 ;{ }^{* *} p<.01 ;{ }^{*} p<.05 ;{ }^{*} p<.10 ; n=198$

TABLE IV

Mean Climate Scores by Division

\begin{tabular}{|c|c|c|c|c|}
\hline \multirow[b]{2}{*}{$\begin{array}{l}\text { Climate } \\
\text { Variable }\end{array}$} & \multirow[b]{2}{*}{$F$} & \multicolumn{3}{|c|}{ Division } \\
\hline & & $\begin{array}{c}\text { Manufacturing } \\
n=49\end{array}$ & $\begin{array}{c}\text { Corporate } \\
n=104\end{array}$ & $\begin{array}{l}\mathrm{R} \& \mathrm{D} \\
n=45\end{array}$ \\
\hline Freedom & $8.45^{* * *}$ & 12.88 & 15.89 & 15.39 \\
\hline Disinterest & $4.40^{* *}$ & 7.71 & 6.82 & 7.98 \\
\hline Recognition & $6.81^{* * *}$ & 9.19 & 10.83 & 9.70 \\
\hline Encouragement & $4.92^{* *}$ & 16.67 & 18.20 & 16.98 \\
\hline Constraints & 1.26 & 17.42 & 16.88 & 17.88 \\
\hline Coordination & 1.70 & 14.55 & 14.02 & 13.33 \\
\hline
\end{tabular}

${ }^{* * *} p<.001 ;{ }^{* *} p<.01$

Of greater interest to this study are two other results reported in Table III. For all but the coordination variable, the quality of exchange between leader and subordinate (LMX) continued to account for significant and unique variance, even after division and WGX preceded it in the models. Further, data in the table revealed that in all six tests the interaction term of WGX $* \mathrm{LMX}$ was also significant. That is to say, even though it followed the three main effect terms and the other two first-level interaction terms (division * WGX and division * LMX), the interaction of work group exchange and leader/subordinate exchange continued to be an important factor and still accounted for significant variance on each climate factor.

To examine the nature of these interactions, scores for WGX and LMX were dichotomized into low vs. high levels of work group exchange, and out-group vs. in-group exchanges for leader/subordinate relationships. [Note that the terms out-group and in-group have been used by Graen and colleagues [8], [9], [13] to represent dyadic exchanges of low and high quality, respectively.] Mean values for the climate variables were then computed for each WGX * LMX condition and used to plot Figs. 1-6.

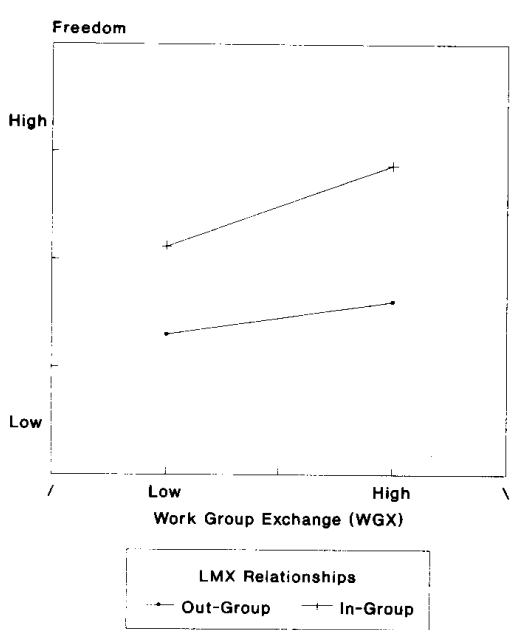

Fig. 1. WGX X LMX interaction for climate variable: Freedom.

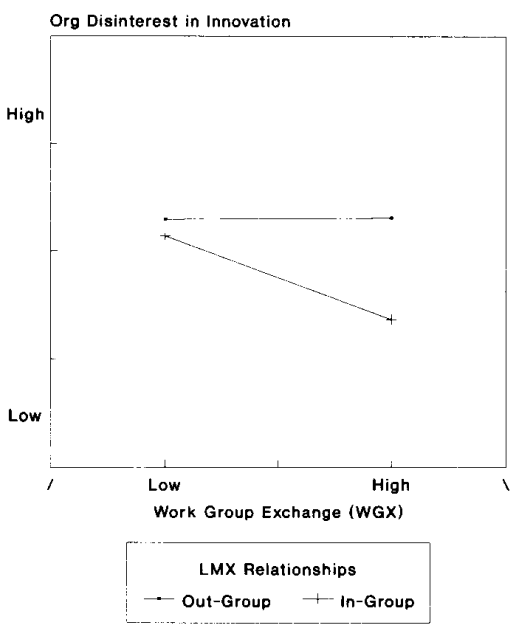

Fig. 2. WGX X LMX interaction for climate variable: Disinterest.

As the figures reveal, in all six cases, the most desirable climate conditions (i.e., highest scores on freedom, recognition, encouragement, and coordination, and the lowest scores on disinterest and constraints) were reported by subordinates who experienced positive exchanges with both work group members and their manager. The least desirable scores on three of the climate factors (i.e., freedom, recognition, and constraints) were reported by subordinates experiencing negative exchanges with both work group members and their manager.

\section{Discussion}

Results from this study contribute to our understanding of work climate in two ways. First, data are reported which offer empirical corroboration for earlier studies. In this sense, the current investigation can be looked upon as validating previous research in that: (a) differences in several climate perceptions were found to exist among 


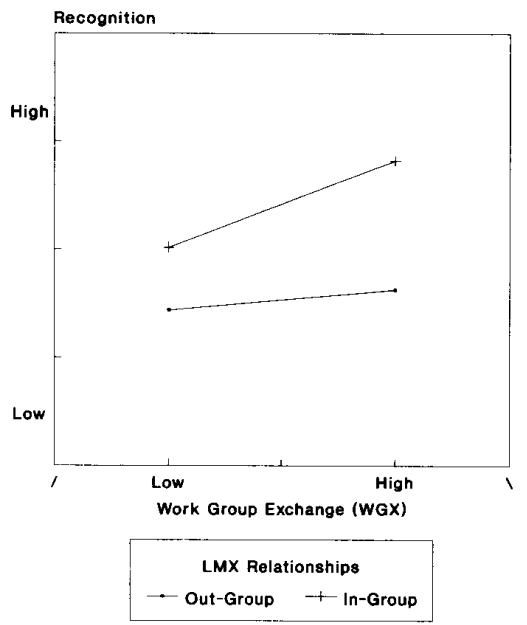

Fig. 3. WGX X LMX interaction for climate variable: Recognition.

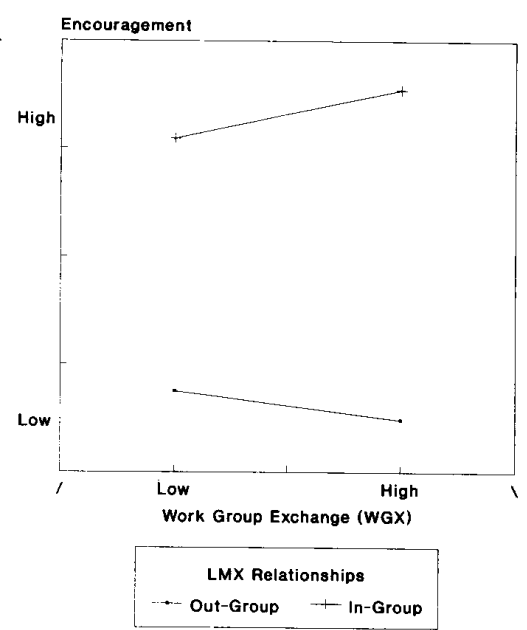

Fig. 4. WGX X LMX interaction for climate variable: Encouragement.

functional divisions; (b) positive correlations were found between higher quality work exchanges (WGX) and perceptions of freedom, recognition, encouragement, and coordination; (c) negative correlations existed between WGX and perceptions of disinterest and innovative constraints; (d) positive correlations were found for employees reporting higher quality exchanges (LMX) with their managers and perceptions of freedom, recognition, and encouragement; (e) negative correlations were reported for employees with higher LMX relationships and their perceptions of disinterest and constraints.

But the study makes a contribution beyond this validational component. It was structured so as to investigate how three sources of subordinate perceptions (i.e., divisional affiliation, WGX, and LMX) combined to explain variance in the climate experienced by employees. Fur-

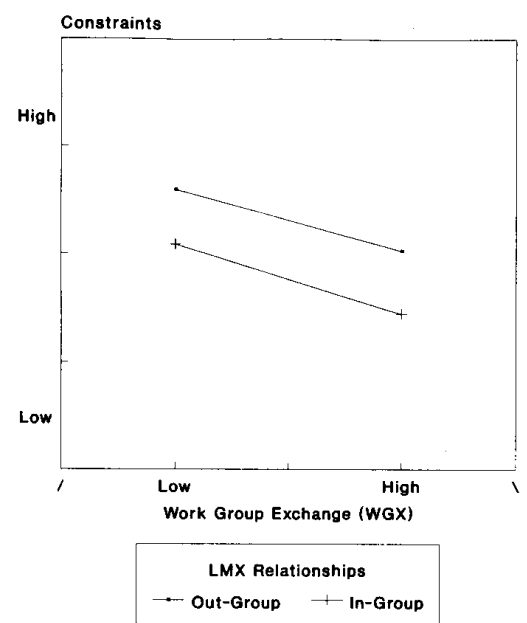

Fig. 5. WGX X LMX interaction for climate variable: Constraints.

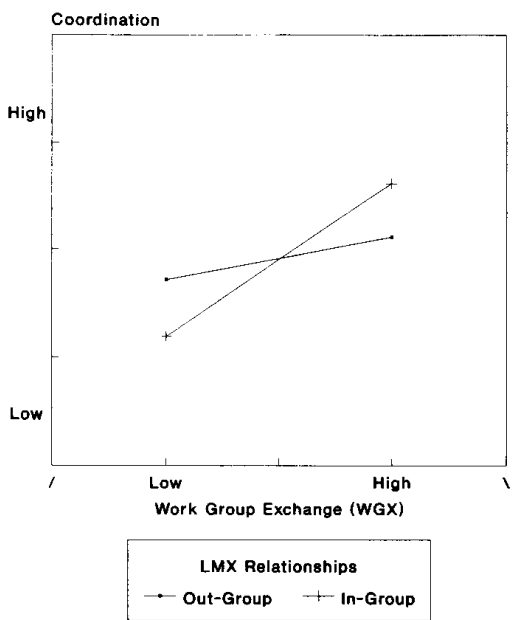

Fig. 6. WGX X LMX interaction for climate variable: Coordination.

ther, analyses were configured so as to evaluate the perceptual sources in descending order, according to the relative control a manager has in affecting them. Divisional affiliation, the factor with the least managerial control, was always given the first opportunity to account for variance in climate perceptions, followed by the next least controllable factor -interactions among members of the work group itself (WGX). The leader/subordinate relationship (LMX) was always the last predictor variable entered, and therefore, given the least chance for accounting for additional variance in climate perceptions. By testing for interactive relationships among the three sources of perceptions, and controlling order of entry to the statistical models, this study extends the research on innovative climate into new areas.

Before discussing implications of findings from this second area of contribution, a few comments are in order 
regarding divisional affiliation and work group exchanges as main effects. As reported above, differences were found among the three divisions on measures of freedom, disinterest, recognition, and encouragement (see Tables III and IV). It is interesting to note, however, that employees from the manufacturing division were not always the ones who reported climate conditions least favorable to innovative actions, nor did R \& D employees always report conditions most conducive to innovation. In fact, on all four climate factors where divisional affiliation had a significant main effect, it was the corporate division which consistently scored the most favorable marks (see Table IV). Thus, if there is truth to the commonly held maxim that the more conducive the climate the more innovative the employees, then, if taken at face value, these data suggest that this particular company should expect the most innovative behaviors from members of its corporate staff.

However, there is a shortcoming in this logic. First of all, scores for the climate variables used in this study were assessed using perceptual and, therefore, relative scales. Assume, for example, that innovative freedom could be measured with some objective instrument and that after applying this instrument we found two employees, one from manufacturing and one from $\mathrm{R} \& \mathrm{D}$, had the same freedom score of 10 utils. Since the objective measure produced identical scores, might we also expect their perceptual assessment of this climate measure to be equal? Perhaps. But more likely perceptual responses would differ because employees in the two divisions probably have quite different expectations about the level of freedom they believe should exist, given the nature of their tasks, skills, and level of training. Thus, 10 utils of freedom for the manufacturing employee may be perceived as very high, whereas the R \& D employee might perceive 10 utils of freedom to be very low.

This being the case, it may be inappropriate to make direct comparisons of the "absolute" perceptual scores on climate variables across divisions. A more fitting analysis would be to hold these differences constant while assessing the impact of other factors contributing to perceptual variations. In effect, this is exactly what was done by controlling the order in which factors were added to the regression analyses. Since division affiliation was always entered first, it was, in essence, held constant while testing relationships between the climate factors and the other predictor variables.

With regard to the relationship between WGX and the climate variables, a clear and consistent pattern emerged from these data. The quality of interaction a subordinate had with other members of his/her work group was definitely associated with perceptions subordinates developed about the work climate. If we adhere to the aforementioned maxim that a conducive climate will result in more innovative behaviors, then it is apparent that work group dynamics can act to either foster or inhibit an innovative environment.

From a managerial perspective, the consistent relation- ship between WGX and desirable climate conditions is a double-edged sword. On the positive side, the presence of a strong and favorable work group interaction may be able to overcome, or at least minimize, other factors (i.e., resource scarcity, time pressures, etc.) which might normally denigrate an innovative climate. On the negative side, if the exchange between work group members is dysfunctional, vis-a-vis an innovative climate, WGX dynamics may neutralize environmental factors which would customarily foster a creative atmosphere.

Unfortunately, the quality of work group dynamics is not something which can be legislated by managerial decree. As stated earlier, however, while managers may have less control over WGX than other climate-related factors (e.g., LMX), there are any number of managerial strategies which can be used to influence the degree of work group interactions. For example, a manager might find that he/she can obtain more desirable WGX conditions by manipulating such things as task interdependencies, intragroup conflict and competition, creating or collapsing subgroups, or simply by redesigning spatial arrangements among work group members to influence communication patterns. [For a more detailed discussion, readers are encouraged to examine any number of very good books/articles on this topic [12], [16], [20], [25], [26], [41].] Suffice to say that although managers may not be able to directly control the quality of exchange among work group members, there are tactics which can be used to create conditions where a more desirable WGX can develop.

On the other hand, the quality of dyadic exchange between leader and subordinate (LMX) is something over which the manager can have a more direct effect [15], [36]. While important in and of itself, this capacity to orchestrate the relationship with subordinates takes on additional meaning within the context of this study. As shown in Table I, significant correlations were found between LMX and subordinate perceptions of five of the climate factors (coordination being the exception). These data indicate that as the dyadic exchange improves in quality (i.e., as LMX scores increase), subordinates are significantly more likely to perceive climate conditions which Amabile and others [2], [3], [5], [7], [31], believe fosters, stimulates, and encourages innovation and creative problem solving.

Further, the fact that LMX continued to account for significant variance in the same five climate factors after divisional affiliation and WGX preceded it in the regression analyses, indicates rather strongly that the dyadic interaction between leader and subordinate taps into a unique and potentially powerful segment of a subordinate's perceived work environment. In other words, even after removing the variance accounted for by divisional affiliation, and all the preexisting elements subsumed therein (e.g., training, skill levels, education, tradition \& history, expectations, etc.), and even after removing the variance accounted for by group interactions and the powerful effects of socially constructed realities in- 
cumbent in WGX, the quality of exchange which develops between a leader and subordinate remains an important and nonredundant source of climate related perceptions.

However, a note of psychometrically-induced "caution" must be introduced here. These data were collected using a cross-sectional design, and because of this cannot be used to argue for causality. They do not prove that higher LMX causes more favorable climate conditions (nor, for that matter, that divisional affiliation or WGX causes subordinate perceptions). Still, since studies have demonstrated that managers can do something to improve relationships with subordinates [15], [36], enhancing the LMX exchange is, if nothing else, at least a proactive step which may set the stage for greater innovative activities on the part of subordinates. [It should also be noted that in several longitudinal research endeavors, where causality could be demonstrated, the quality of exchange between leader and subordinate has been shown to have a causal impact on a number of organizationally relevant factors such as turnover [14], job satisfaction [9], [15], career progress [52], and managerial development [36].]

A final contribution this study makes toward understanding climate comes from testing the interactive effects of divisional affiliation, WGX, and LMX. For the most part, previous empirical studies in this area have primarily focused on main effect relationships and have not examined the possible interactive nature of perceptual sources. As reported in Tables II and III, a number of significant interaction terms were found in these data. Although divisional affiliation was found to interact with WGX and/or LMX in a number of tests (e.g., freedom, disinterest, and recognition), it did not seem to play a very consequential role beyond its influence as a main effect variable.

On the other hand, the interaction between WGX and LMX was consistently significant across all six regression analyses. What this suggests is that the relationship between WGX and LMX in explaining variance on these climate factors goes beyond simple additive effects. That is, a synergy appears to exist between WGX and LMX such that they work interdependently to account for climate perceptions. As explained earlier, an attempt to capture the nature of this interdependency was made by dichotomizing the two factors and plotting the six climate factors in Figs. 1-6. [It should be noted that by dichotomizing these factors we sacrifice some of their statistical power, so the resulting figures are somewhat "weakened" representations of the actual interactions.]

As illustrated in all six figures, climate perceptions most favorable to innovative activities were found when both WGX and LMX scores were the highest. In other words, when subordinates had a high quality exchange with both work group members and their manager, the perceived environment was most conducive to innovation. Further, half the figures illustrate that perceptions of climate factors least conducive to innovation were found when both WGX and LMX were low. In concert, these data suggest that in order to optimize conditions for innovative activity,

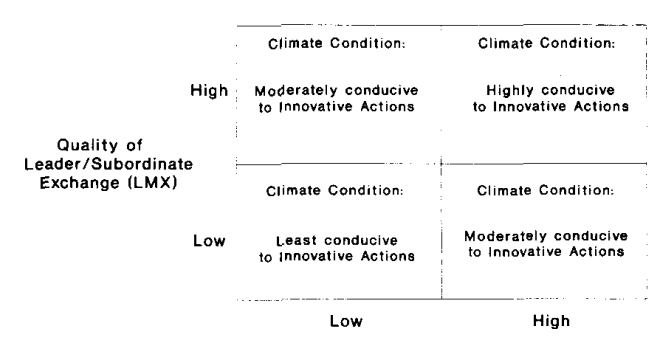

Quality of Work Group Exchange (WGX)

Fig. 7. Creating an innovative climate with WGX and LMX.

managerial actions should be taken to develop high quality relationships with each subordinate (LMX) as well as creating work groups characterized by positive member interactions (WGX).

These findings have been synthesized and are graphically illustrated in Fig. 7. Overall climate conditions least favorable to innovative activities would be experienced by subordinates who perceive low quality exchanges with their work group peers and their direct supervisor. A moderately favorable climate would be perceived by subordinates where either the work group or the leader/subordinate exchange is of high quality. However, the goal of any manager interested in fostering innovation would be to reach the high-LMX and high-WGX quadrant. Under these conditions, subordinates would experience a work climate which would be most conducive to innovation and creative problem solving. Further, the interactive effects of WGX and LMX appear relevant across divisional lines. That is, a manager in manufacturing would find the model depicted in Fig. 7 as appropriate as a manager in R \& D or corporate (or, we surmise, in any functional breakdown).

To summarize, the literature on innovation indicates that the climate within which employees perform their tasks will have a significant impact on the opportunity and motivation to act in an innovative fashion [1]-[3], [29], [30]. What data from this study empirically documents is that divisional affiliation, work group interactions (WGX), and the quality of exchange between leaders and their subordinates (LMX) are significantly related to the perceptions a subordinate will develop regarding this climate. Further, it was demonstrated that the LMX factor, the factor argued to be most controllable by the manager, remains a strong predictor of innovative climate perceptions even after accounting for variance explained by the other two sources. Finally, data indicate that there is a significant interactive influence on climate associated with the interdependency of WGX and LMX, an association which goes beyond the influence of simple main effects. Future research should be undertaken to validate the present findings. Where the current study utilized a cross-sectional design, it would prove especially useful if future investigations could engage in longitudinal examinations in order to permit the testing of causal inferences. 


\section{REFERENCES}

[1] A. Abbey and J. W. Dickson, "R \& D work climate and innovation in semiconductors," Academy of Management Joumal, vol. 26(2), pp. $362-368,1983$.

[2] T. M. Amabile, "A model of creativity and innovation in organizations." in Research in Organizational Behavior, B. M. Staw and L. L. Cummings, Eds., vol. 10, pp. 123-167, 1988.

[3] T. M. Amabile and S. S. Gryskiewicz, "Creativity in the R \& D laboratory" Tech. Rep. 30, Center for Creative Leadership, Greensboro, N.C., 1987.

[4] F. M. Andrews, "Social and psychological factors that influence the creative process," in Perspectives in Creativity, I. A. Taylor and J. W. Getzels, Eds., Chicago: Aldine, pp. 117-145, 1975.

[5] F. M. Andrews and G. F. Farris, "Supervisory practices and innovation in scientific teams," Personnel Psychology, vol. 20, pp $497-575,1967$.

[6] N. R. Baker and J. R. Freeland, "Structuring information flow to enhance innovation," Management Sci., vol. 19(1), pp. 105-116, 1972.

[7] L. L. Cummings, "Organizational climates for creativity," Academy of Management Joumal, vol. 8, pp. 220-227, 1965.

[8] F. Dansereau, G. B. Graen, and B. Haga, "A vertical dyad linkage approach to leadership within formal organizations: A longitudinal investigation of the role making process," Organizational Behavior and Human Performance, vol. 131, pp. 46-78, 1975.

[9] D. Duchon, S. G. Green, and T. D. Taber, "Vertical dyad linkage: A longitudinal assessment of antecedents, measures, and consequences," Journal of Applied Psychology, vol. 71, pp. 56-60, 1986.

[10] G. A. Forehand and B. V. H. Gilmer, "Environmental variation in studies of organizational behavior," Psychological Bulletin, vol. 62 , pp. 361-382, 1964.

[11] B. S. Georgopolous and F. C. Mann, The Community General Hospital, New York: McMillan, 1962.

[12] P. S. Goodman, E. Rawlin, and M. Schminke, "Understanding groups in organizations," Research in Organizational Behavior, vol 9, pp. $121-173,1987$.

[13] G. B. Graen and J. F. Cashman, "A role-making model in formal organizations: A developmental approach," in Leadership Frontiers, J. G. Hunt and L. L. Larson, Eds., Kent, OH: Kent State Univ. Press, 1975.

[14] G. B. Graen, R. Liden, and W. Hoel, "Role of leadership in the employee withdrawal process," Joumal of Applied Psychology, vol. 67, pp. $868-872,1982$.

[15] G. B. Graen, M. Novak, and P. Sommerkamp, "The effects of leader-member exchange and job design on productivity and job satisfaction: Testing a dual attachment model," Organizational Behavior and Human Performance, vol. 30, pp. 109-131, 1982.

[16] J. R. Hackman, "Group influences on individuals," in Handbook of Industrial and Organizational Psychology, Chicago: Rand-McNally, 1976, pp. 1455-1525.

[17] D. Hall and E. Lawler, "Unused potential in research development organizations," Research Management, vol. 12, pp. 339-354, 1969.

[18] L. A. James and L. R. James, "Integrating work environment perceptions: Explorations into the measurement of meaning," Journal of Applied Psychology, vol. 74(5), pp. 739-751, 1989.

[19] L. R. James and A. P. Jones, "Organizational climate: A review of theory and research," Psychol. Bull., vol. 81, pp. 1096-1112, 1974.

[20] L. M. Jewell and H. J. Reitz, Group Effectiveness in Organizations Glenview, IL: Scott-Foresman, 1981.

[21] R. J. Kanter, "When a thousand flowers bloom," Research in Organizational Behavior vol. 10, pp. 169-211, 1988.

[22] S. Kerr and J. M. Jermier, "Substitutes for leadership: Their meaning and measurement," Organizational Behavior and Human Performance, vol. 22, pp. 375-403, 1978.

[23] S. W. Kozlowski and M. L. Doherty, "Integration of climate and leadership: An examination of a neglected issue," Journal of $A p-$ plied Psychology, vol. 74(4), pp. 546-553, 1989.

[24] G. Litwin and R. Stringer, Motivation and Organizational Climate. Cambridge, MA: Harvard University Press, 1968.

[25] R. J. Lichtman and I. M. Lane, "Effects of group norms and goal setting on productivity," Group \& Organizational Studies, pp. 406-420, Dec. 1983.

[26] J. W. Lorsch and P. R. Lawrence, Managing Group and Intergroup Relations. Homewood, IL: Irwin \& Dorsey, 1972.
[27] P. R. Nayak and J. M. Ketteringham, Breakthroughs. New York, Rawson Associates, 1986.

[28] J. E. Newman, "Understanding the organizational structure-job attitude relationship through perceptions of the work environment," Organization Behavior and Human Performance, vol 14, pp. 371-397, 1975.

[29] J. G. Paolillo and W. B. Brown, "How organizational factors affect R \& D innovation," Research Management, vol. 7, pp. 12-15, 1978

[30] J. G. Paolillo and W. B. Brown, "A multivariate approach to perceived innovation in R \& D subsystems," IEEE Trans. Eng. Manage., vol. EM-26, pp. 36-39, 1979.

(31] D. C. Pelz and F. M. Andrews, Scientists in Organizations. New York, Wiley, 1966.

[32] G. N. Powell and D. A. Butterfield, "The case for subsystem climates in organizations," Academy of Management Rev., vol. 3, pp. $151-157,1978$.

[33] F. J. Roethlisberger and W. J. Dickson, Management and the Worker. Cambridge, MA: Harvard University Press, 1939.

[34] G. Salancik and J. Pfeffer, "A social information processing approach to job attitude and task design," Administrative Science Quarterly, vol. 23, pp. 224-253, 1978.

[35] H. M. Sapolsky, "Organizational structure and innovation," Journal of Business, vol. 40, pp. 497-510, 1967.

[36] T. A. Scandura and G. B. Graen, "Moderating effects of initial leader-member exchange status on the effects of a leadership intervention." Journal of Applied Psychology, vol. 69(3), pp. 428-436, 1984.

[37] B. Schneider, "The perception of organizational climate: The customer's view," Journal of Applied Psychology, vol. 57, pp. 248-256, 1973.

[38] B. Schneider, "Organizational climates: An essay," Personnel Psychology, vol. 28, pp. 447-479, 1975.

[39] B. Schneider and C. J. Bartlett, "Individual differences and organizational climate, II: Measurement of organizational climate by the multitrait-multirater matrix," Personnel Psychology, vol. 23, pp. $493-512,1970$

[40] B. Schneider and A. E. Reichers, "On the etiology of climates," Personnel Psychology, vol. 36, pp. 19-39, 1983.

[41] M. E. Shaw, Group Dynamics: The Psychology of Small Group Behavior (3rd ed.), New York: McGraw-Hill, 1981.

[42] C. R. Shepard, Small Groups. San Francisco: Chandler, 1954.

[43] W. E. Souder and A. K. Chakrabarti, "Industrial innovations: A demographical analysis," IEEE Trans. Eng. Manage., vol. EM-26, pp. 101-109, 1979.

[44] C. W. Taylor, "Variables related to creativity and productivity among men in two research laboratories," in Scientific Creativity: Its Recognition and Development, C. W. Taylor and F. Barron, Eds., New York, Wiley, 1963, pp. 228-250.

[45] C. W. Taylor, "Can organizations be creative too?" in Climate for Creativity, C. W. Taylor, Ed., New York: Pergamon Press, 1972, pp. $1-15$.

[46] D. L. Thistlewaite, "The college environment as a determinant in research potentiality," in Scientific Creativity: Its Recognition and Development, C. W. Tayler \& F. Barron, Eds. New York: Wiley, 1963, pp. $205-216$.

[47] E. P. Torrance, Rewarding Creative Behavior. Englewood Cliffs, NJ: Prentice-Hall, 1972.

[48] M. L. Tushman and W. L. Moore, Readings in the Management of Innovation. Marshfield, MA: Pitman Publishing, Inc., 1982.

[49] A. H. Van de Ven, "The process of adopting innovations in organizations: Three cases of hospital innovations," in Designing for Technological Change, B. Guile, E. Laumann, and G. Nadler, Eds., Washington, DC: National Academy Press, 1990.

[50] R. P. Vecchio, Organizational Behavior. New York: Dryden Press, 1988.

[51] R. W. Vegso, "Organizational characteristics that influence innovative behavior," Unpublished Ph.D. dissertation, University of Cincinnati, 1976.

[52] M. Wakabayashi and G. B. Graen, "The Japanese career progress study: A 7-year follow-up," Joumal of Applied Psychology, vol. 69(4), pp. 603-614, 1984.

[53] M. A. Welsh and C. H. Matthews, "The innovative climate scale," Unpublished research, University of Cincinnati. 


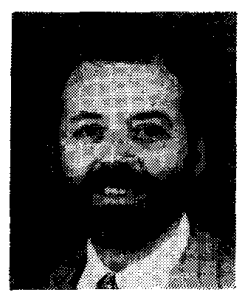

Kenneth J. Dunegan received the Ph.D, degree from the University of Cincinnati. He is an assistant professor of organizational behavior at Cleveland State University, and has published in IEEE Transactions in ENGINEERING ManageMENT, Organizational Behavior and Human Decision Processes, Decision Sciences, Journal of Management, Review of Business, Journal of Management Systems, and Mid-American Journal of Business. His research interests include management of the innovation process, dyadic leadership, and behavioral decision making. He has served as consultant to a number of organizations and, prior to his involvement in the Ph.D. program at U.C., held managerial positions in the private sector.

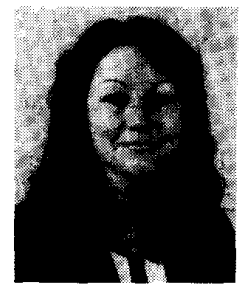

Pamela Tierney is currently a doctoral candidate at the University of Cincinnati Department of Management. Her main research interests are leadership and corporate innovation. She has been involved in a number of field studies focusing on various aspects of organizations, both micro and macro, and their relation to the innovation process. She is currently completing her doctoral dissertation, a field study of investigating the role of leadership, work context, and individual attributes on the initiation stage of innovation in an R \& D setting. In addition to her research, she periodi- cally works as a management consultant in the area of corporate innovation.

Ms. Tierney is a member of the Academy of Management.

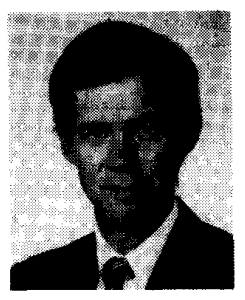

Dennis Duchon received the Ph.D. degree from the University of Houston.

At present, he is an associate professor of management at the University of Texas at San Antonio where his research interests include strategic decision making, organizational design, and R \& D management. Dr. Duchon has had his work published in IEEE TRANSACTIONS ON ENGINEERING MANAGEMENT, Journal of Applied Psychology, Organizational Behavior and Human Decision Processes, Journal of Management, Decision Sciences, Journal of Applied Behavioral Science, and MIS Ouarterly. Prior to graduate school Dr. Duchon worked for a consulting firm in Hong Kong, managed a graphics operation, and worked as a newspaper reporter.

$\mathrm{He}$ is a member of the Academy of Management, the Decision Sciences Institute, and the IEEE. 